\title{
Whole body air displacement plethysmography compared with hydrodensitometry for body composition analysis
}

\author{
Odile Dewit, N J Fuller, Mary S Fewtrell, M Elia, J C K Wells
}

\begin{abstract}
Aims-To assess the acceptability and feasibility of whole body air displacement plethysmography in children and to determine its precision and agreement with hydrodensitometry, an appropriate reference method.

Methods-Age specific two component model equations were used to predict fat mass from body density in 22 children aged 8-12 years and in 10 adults for comparison of methods. Precision for each method was established from duplicate measurements.

Results-Plethysmography was accepted more readily than hydrodensitometry $(100 \%$ v $69 \%$ provided duplicate measurements). Precision for fat mass in children was $0.38 \mathrm{~kg}$ by plethysmography and $0.68 \mathrm{~kg}$ by hydrodensitometry, and results were similar in adults. The mean (SD) fat mass in children was $6.9 \mathrm{~kg}(4.0)$ and $6.7 \mathrm{~kg}(4.2)$ by plethysmography and hydrodensitometry, respectively, but $95 \%$ limits of agreement between methods were large $(-4.1 \mathrm{~kg}$ to $3.5 \mathrm{~kg}$ fat).

Conclusion-Plethysmography was more readily accepted and had better precision than hydrodensitometry. It also provided similar body composition results for the group but not for all individual children. (Arch Dis Child 2000;82:159-164)
\end{abstract}

MRC Dunn Clinical Nutrition Centre, Hills Road, Cambridge CB2 2DH, UK N J Fuller M Elia

MRC Childhood Nutrition Research Centre, Institute of Child Health, London WC1N 1EH, UK M S Fewtrell J C K Wells

Clinical Pharmacology Department,

SmithKline Beecham Pharmaceuticals, New Frontiers Science Park (South), Third Avenue, Harlow CM19 5AW, UK

O Dewit

Correspondence to: Dr N J Fuller, 3 Cherry Hinton Court, Cherry Hinton Road, Cambridge CB1 7AL, UK

Accepted 14 September 1999 until now, this traditional approach required research methodology, involving full submersion of the subject under water, which has hin- dered clinicians or field workers when assessing children, especially the very young or sick and those frightened of water. The recent development of whole body air displacement plethysmography ${ }^{5}$ offers a potentially advantageous alternative to hydrodensitometry for measuring body volume because it is minimally invasive, does not require highly trained investigators, and the equipment could be incorporated easily into a clinical investigations hospital laboratory. This technique has already been validated in adults, ${ }^{5}$ but not in children.

Therefore, the aims of our study were to: (1) assess the acceptability and feasibility of whole body air displacement plethysmography in children; (2) assess the precision of the method in children; (3) assess its agreement with hydrodensitometry, taken as the reference method, for body composition analysis in children using the two component model; and (4) compare the findings in children with those obtained in a group of adult subjects.

\section{Methods}

SUBJECTS

Twenty eight healthy children, 17 boys and 11 girls, aged 5-14 years, were included in our study, which was part of a larger study ${ }^{6}$ of body composition analysis in children. Twenty two of these (13 boys, nine girls; median age, 9.8 years; range, 8.1 to 12.9 years; mean (SD) weight, 33.15 (7.36) kg; mean (SD) height, $1.39(0.10) \mathrm{m}$; mean (SD) body mass index (BMI), $16.9(2.3) \mathrm{kg} / \mathrm{m}^{2}$ ) were involved in the comparison of whole body air displacement plethysmography with hydrodensitometry, which included precision estimates obtained by repeated hydrodensitometry measurements on each of this group. Ten children (four from the group of 22, and an additional six (seven boys, three girls: median age, 8 years; range, 5 to 14 ; mean (SD) weight, 29.65 (9.68) kg; mean (SD) height, 1.30 (0.16) m; mean (SD) BMI, $\left.17.0(1.4) \mathrm{kg} / \mathrm{m}^{2}\right)$ ) participated in the assessment of plethysmography precision. A further ten children (two boys, eight girls: median age, 8.5 years; range, 8 to 12 years) who were originally recruited into our study were excluded from the analysis because of practical difficulties that prevented duplicate hydrodensitometry measurements. Such difficulties, which invalidated density measurements, comprised the following: (a) incomplete submersion; (b) body weight supported partially by the water tank sides or floor (that is, not exclusively taken by the weighing frame); and (c) imperfect seal around the mouthpiece during lung volume 
measurement that allowed exchange of gas with ambient air. If one of the two measurements did prove to be flawed by any of these factors, the child was not asked to undergo a third measurement; equally, if the children showed any sign of distress or discomfort during the measurement, it was not pursued further. Although air displacement plethysmography was much easier, with better compliance than hydrodensitometry, there were still some potential pitfalls to be avoided, including movement by the subject within the chamber, loose fitting clothing and unsecured hair, and excessive or sudden changes in ambient pressure during the measurement, which might be caused by extraneous events such as the opening and closing of particular doors elsewhere in the building.

Children were recruited by letter from local schools or swimming clubs, and informed written consent was obtained from the parents of all children. One parent was present during all investigations, precautions were taken to make the children feel comfortable and a paediatrician was always present. Ten healthy adult volunteers (five men, five women: median age, 29.5 years; range, 19 to 41 years; mean (SD) weight, 62.0 (6.5) kg; mean (SD) height, 1.71 (0.08) m; mean (SD) BMI, $21.2(1.6) \mathrm{kg} / \mathrm{m}^{2}$ ) were also included in our study for comparison of methods and assessment of precision. Informed written consent was obtained from each. The investigations were approved by the MRC Dunn Nutrition Centre ethics committee and the local research ethics committee of the Cambridge and Huntingdon Health Authority.

PROTOCOL

Plethysmography and hydrodensitometry measurements were undertaken on the same day, except in two (weight stable) adults for whom measurements were obtained within a couple of days of each other. Height was measured to the nearest $0.5 \mathrm{~cm}$ using a wall mounted stadiometer (Holtain, Dyfed, UK). Body weight was measured to the nearest $0.01 \mathrm{~kg}$ using calibrated electronic scales.

Whole body air displacement plethysmography was performed using the BODPOD body composition system (Life Measurement Instruments, California, USA) according to the manufacturer's instructions and recommendations. These measurements were undertaken immediately before hydrodensitometry, with the subjects wearing a tight fitting swimsuit and swimming cap. The procedure involved a volume calibration with and without a 50 litre metal cylinder. Subjects entered the BODPOD and sat inside the anterior chamber (450 litres), which was connected to a rear measuring chamber (300 litres) via oscillating diaphragms (used to induce pressure changes in the anterior chamber), and breathed normally (relaxed tidal breathing). The recommended procedure, consisting of two measurements of body volume (50 seconds each), was adopted and when, occasionally, body volumes differed by more than $150 \mathrm{ml},{ }^{7}$ the system required that a third measurement be performed. The final result reported by the BODPOD instrumentation was the mean of the two (or the two closest) measurements. The whole procedure was carried out twice in the group of 10 children and in the adult group to obtain duplicate measurements of body volume by plethysmography for calculation of method precision.

Hydrodensitometry was performed by a single highly experienced investigator using a purpose built water tank to obtain weight when fully submerged under water. A helium dilution technique was used to obtain a measurement of lung volume simultaneously with the measurement of weight under water. ${ }^{4}$ Two consecutive measurements were made in each subject to calculate hydrodensitometry precision.

CALCULATIONS OF BODY VOLUME

In the whole body air displacement plethysmography technique, the instrumentation measures the volume of air in the anterior chamber, using pressure changes induced by the oscillating diaphragm according to Boyle's laws of relations between volume, pressure, and temperature of gases, and provides raw body volume (raw BV; litres) for each subject simply from the difference between the volumes of air in this chamber, with and without the subject being present. However, because the raw BV measurement would have been adversely influenced by adiabatic conditions created by the subject's presence (this warmer air, approximately $37^{\circ} \mathrm{C}$, is more compressible than the ambient air), the manufacturer's software applies certain corrections to the thoracic gas volume ( $\mathrm{TGV}$; litres) and air next to the skin (using the surface area artefact, SAA; litres) to adjust to isothermal conditions for obtaining each subject's actual body volume ${ }^{7}$ :

Actual body volume (litres) = raw $\mathrm{BV}+0.4 \mathrm{TGV}$ - SAA.

Where, TGV was predicted from functional residual capacity (FRC; litres) and tidal volume (TV; litres) ${ }^{8}$ :

$\mathrm{TGV}=\mathrm{FRC}+0.5 \mathrm{TV}$.

FRC was predicted using the equations of Crapo and colleagues ${ }^{9}$ and TV was assumed to be a constant 1.2 litres for men and 0.7 litres for women.

In addition, SAA was obtained from the product of predicted whole body surface area $\left(\mathrm{SA} ; \mathrm{cm}^{2}\right)$ and a negative constant $(\mathrm{k}$; personal communication, Life Measurement Instruments, 1998):

$\mathrm{SAA}=-\mathrm{k} \cdot \mathrm{SA}$.

SA was calculated according to Du Bois and Du Bois ${ }^{10}$ :

$\mathrm{SA}=71.84 \cdot \mathrm{W}^{0.425} \cdot \mathrm{H}^{0.725}$

W was body weight $(\mathrm{kg})$ and $\mathrm{H}$ was height (cm).

Whole body air displacement plethysmography estimates TGV from FRC prediction equations derived in adults aged 15-91 years. ${ }^{9}$ Because the ages of the children in our study were below the lower limit of this range, TGV was also calculated using more appropriate 
prediction equations specifically derived in children: FRC was predicted using the equations of Rosenthal and colleagues ${ }^{11}$; and TV was predicted using the equation of Zapletal et $a l .{ }^{12}$ Subsequently, individual body volumes were calculated using TGV values predicted from these child specific equations instead of the adult specific ones.

In the well established hydrodensitometry technique, body volume was calculated as the difference of body mass in air and in water, correcting for density of water and measured lung volume. ${ }^{4}$

Body density was calculated as body mass/ volume ( $\mathrm{kg} /$ litre) for each method. Body fat (\%) was calculated according to the following equations, because of the use of different constraints (see discussion):

for adults, ${ }^{3} \%$ fat $=(495 /$ body density $)-450$

for children, ${ }^{6} \%$ fat $=(527 /$ body density $)-485$

where body density is in $\mathrm{kg} /$ litre. Fat mass was calculated from \%fat and body weight.

\section{STATISTICS}

Standard deviation (SD) of the differences between duplicate measurements, for both hydrodensitometry and plethysmography $\left(\mathrm{S}_{\mathrm{H}}\right.$ and $S_{P}$, respectively), was calculated as the square root of the sum of squared differences between duplicates divided by $n \cdot{ }^{13}$ Estimates of precision for single measurements obtained using these techniques were calculated by dividing $S_{H}$ and $S_{P}$ by $\sqrt{2}$.

Agreement between hydrodensitometry and plethysmography was assessed using the method of Bland and Altman ${ }^{13}$; where, bias was calculated as the mean difference between methods (hydrodensitometry minus plethysmography) and 95\% limits of agreement were calculated as the bias \pm 2 SD of the differences between methods. Ninety five per cent limits of agreement represent the range over which 95\%

Table 1 Body composition analysis by hydrodensitometry and whole body air displacement plethysmography and respective estimates of precision

\begin{tabular}{|c|c|c|c|c|}
\hline & \multicolumn{2}{|c|}{ Hydrodensitometry } & \multicolumn{2}{|c|}{ Plethysmography } \\
\hline & Mean (SD) & Precision & Mean (SD) & Precision \\
\hline \multicolumn{5}{|l|}{ Children $(n=22)$} \\
\hline Body volume (litres) & $31.77(7.39)$ & 0.129 & $31.82(7.39)$ & 0.072 \\
\hline Body density (kg/l) & $1.045(0.018)$ & 0.0042 & $1.044(0.016)$ & 0.0024 \\
\hline Percentage body fat (\%) & $19.2(8.7)$ & 2.05 & $19.9(7.7)$ & 1.15 \\
\hline Fat mass $(\mathrm{kg})$ & $6.7(4.2)$ & 0.68 & $6.9(4.0)$ & 0.38 \\
\hline \multicolumn{5}{|l|}{ Adults $(\mathrm{n}=10)$} \\
\hline Body volume (litres) & $59.4(5.9)$ & 0.148 & $58.8(5.9)$ & 0.071 \\
\hline Body density (kg/l) & $1.046(0.019)$ & 0.0028 & $1.053(0.022)$ & 0.0011 \\
\hline Percentage body fat $(\%)$ & $23.5(8.8)$ & 1.28 & $20.2(9.6)$ & 0.50 \\
\hline Fat mass $(\mathrm{kg})$ & $14.5(5.3)$ & 0.74 & $12.4(5.7)$ & 0.30 \\
\hline
\end{tabular}

Precision was calculated by dividing the standard deviation of differences between duplicate measurements $\left(\mathrm{S}_{\mathrm{H}}\right.$ or $\left.\mathrm{S}_{\mathrm{P}}\right)$ by $\sqrt{2}$.

Table 2 Comparison between hydrodensitometry $(H)$ and plethysmography $(P)$

\begin{tabular}{llllll}
\hline & \multicolumn{2}{c}{ Children $(n=22)$} & & \multicolumn{2}{l}{ Adults $(n=10)$} \\
\cline { 2 - 3 } \cline { 5 - 6 } \cline { 5 - 6 } & Bias $(H-P)$ & $\begin{array}{l}\text { 95\% limits of } \\
\text { agreement }\end{array}$ & & Bias $(H-P)$ & $\begin{array}{l}\text { 95\% limits of } \\
\text { agreement }\end{array}$ \\
\hline Body volume (litres) & -0.05 & -0.72 to 0.63 & & $0.56^{\star}$ & -0.50 to 1.63 \\
Body density (kg/l) & 0.002 & -0.021 to 0.024 & $-0.007^{\star}$ & -0.018 to 0.003 \\
Percentage body fat $(\%)$ & -0.8 & -11.6 to 10.1 & & $3.3^{\star}$ & -1.3 to 7.9 \\
Fat mass $(\mathrm{kg})$ & -0.2 & -3.8 to 3.3 & $2.1^{\star}$ & -0.9 to 5.2 \\
\hline${ }^{\star} \mathrm{p}<0.01$ & & &
\end{tabular}

$\mathrm{p}<0.01$ of the differences between methods would be expected to fall, giving an indication of whether or not such differences would be acceptable for interchangeable use of these particular methods. SDs of differences between duplicate measurements $\left(S_{H}\right.$ and $\left.S_{P}\right)$ were taken into account in calculation of the SD of the difference between methods $\left(S_{c}\right)$, to correct for the use of means of duplicate measurements in the calculation of the SD of differences between methods $\left(\mathrm{S}_{\text {diff }}\right)$ :

$\mathrm{S}_{\mathrm{c}}=\sqrt{ }\left(\mathrm{S}_{\text {diff }}{ }^{2}+1 / 4 \mathrm{~S}_{\mathrm{H}}{ }^{2}+1 / 4 \mathrm{~S}_{\mathrm{P}}{ }^{2}\right) .^{13}$

The significance of any bias between methods was assessed by the paired $t$ test. The relation between bias and magnitude of parameter was analysed. ${ }^{13}$

Comparison between body volume as measured by the BODPOD body composition system and as calculated using child specific equations for TGV was also was assessed using the method of Bland and Altman. ${ }^{13}$

The SD of the differences between methods $\left(S_{\text {diff }}\right)$ was accounted for by factors inherent to the methodologies themselves (methods precision, $\left.S_{\text {met }}\right)$ and by factors related to biological aspects of the measurements $\left(S_{\text {biol }}\right)$ (such as assumption of gastrointestinal gas volume and prediction of body surface area, and effect of isothermic conditions of air in lungs and air next to the skin) using the following equation ${ }^{6}$ :

$\mathrm{S}_{\text {diff }}^{2}=\mathrm{S}_{\mathrm{met}}^{2}+S_{\text {biol }}^{2}$

where,

$\mathrm{S}_{\mathrm{met}}^{2}=\mathrm{S}_{\mathrm{H}}^{2}+\mathrm{S}_{\mathrm{P}}^{2}$

\section{Results}

Whole body air displacement plethysmography was both feasible and acceptable to all children. Hydrodensitometry was well accepted by about two thirds (22/32) of the children initially recruited into our study. Body composition characteristics of all subjects are presented in table 1 .

The precision of volume measurements and of body composition assessments by plethysmography was approximately twice as good as that obtained by hydrodensitometry for both children and adults (table 1), and was similar for children and adults. The precision for body fat was similar in children and adults when expressed in $\mathrm{kg}$ of fat, but twice as large for children when expressed as percentage fat because the volume of the adults was about twice that of the children.

In children, there was no significant bias between methods (table 2). However, the 95\% limits of agreement between methods (2 SD above and below the bias, table 2) were large: the range of 1.35 litre for body volume translates into $0.045 \mathrm{~kg} /$ litre for body density, $21.7 \%$ for body fat (as percentage of body weight), and $7.1 \mathrm{~kg}$ for fat mass. These large limits of agreement were influenced strongly by the results of four individuals for whom the difference between methods appeared to fall outside the main body of results (fig 1).

In adults, plethysmography significantly $(\mathrm{p}<0.01)$ underestimated body volume (bias, 0.56 litres for a mean volume of 59.1 litres) 


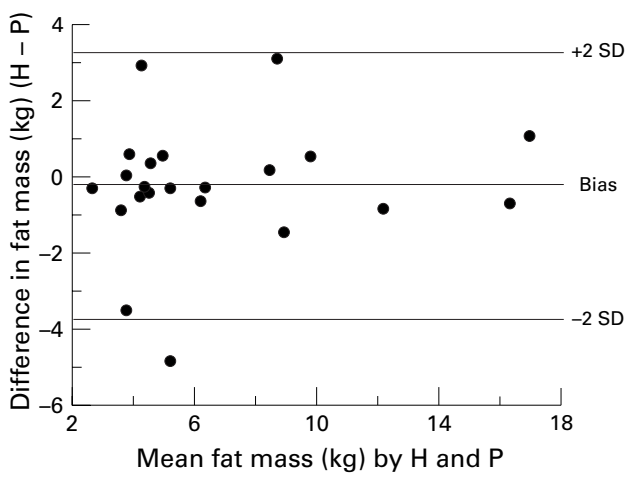

Figure 1 Difference in fat mass between methods against mean fat mass by both methods in individual children.

Each point represents one subject. The central reference line is sited at the value of the bias between methods $(-0.2 \mathrm{~kg})$. The upper and lower reference lines represent the $95 \%$ limits of agreement (3.8 and $-3.3 \mathrm{~kg}$ ). H, hydrodensitometry; $P$, plethysmography.

obtained by hydrodensitometry (table 2). Although the $95 \%$ limits of agreement were slightly greater in absolute terms for adults than for children, they were relatively small because of the greater volume of the adult group. The size of measurement had no influence on the difference between methods.

In children, methodological imprecision accounted for $40 \%$ of the variability between hydrodensitometry and plethysmography for body volume, and $44 \%$ for fat mass. In adults, it accounted for $31 \%$ of the variability for body volume, and $53 \%$ for fat mass.

In the 22 children who were involved in the comparison of plethysmography with hydrodensitometry, mean (SD) TGV was 1.77 (0.32) litres when predicted using child specific equations and $2.05(0.46)$ litres when predicted by the equations in the BODPOD body composition system software. This difference (mean, 0.28; SD, 0.27 litre) was significant $(\mathrm{p}<0.0001)$, and became greater with increasing TGV $\left(r^{2}=0.31 ; \mathrm{p}<0.01\right)$. When child specific TGV values were applied instead of those integral to the BODPOD system, the bias between hydrodensitometry and plethysmography for the group of 22 children became slightly positive (whereas it was slightly negative with the adult version), but was not significant, and the $95 \%$ limits of agreement between the two methods remained wide (table 3 ).

\section{Discussion}

We have assessed the feasibility, acceptability, and validity of whole body air displacement plethysmography for measurement of body volume in children for the first time. The con-

Table 3 Comparison between hydrodensitometry $(H)$ and plethysmography $(P)$ in children $(n=22)$ when using TGV estimated with the BODPOD software (direct $P$ ) or child specific equations (calculated $P$ ) in the assessment of body volume by plethysmography

\begin{tabular}{|c|c|c|c|c|}
\hline & \multicolumn{2}{|l|}{ Direct $P$} & \multicolumn{2}{|l|}{ Calculated P } \\
\hline & Bias $(H-P)$ & $\begin{array}{l}95 \% \text { limits of } \\
\text { agreement }\end{array}$ & Bias $(H-P)$ & $\begin{array}{l}95 \% \text { limits of } \\
\text { agreement }\end{array}$ \\
\hline Body volume (litres) & -0.05 & -0.72 to 0.63 & 0.07 & -0.63 to 0.77 \\
\hline Body density $(\mathrm{kg} / \mathrm{l})$ & 0.002 & -0.021 to 0.024 & -0.019 & -0.025 to 0.021 \\
\hline Percentage body fat (\%) & -0.8 & -11.6 to 10.1 & 0.9 & -10.2 to 12.0 \\
\hline Fat mass $(\mathrm{kg})$ & -0.2 & -3.8 to 3.3 & 0.36 & -3.3 to 4.1 \\
\hline
\end{tabular}

TGV, thoracic gas volume. clusions are fourfold. First, plethysmography is easy, convenient, rapid, and well accepted in 5-14 year old healthy children, and it is likely that most children in this age range, healthy or sick, will be able to comply with this quick measure of body composition. This contrasts with the applicability of hydrodensitometry, which could only be performed successfully in about two thirds of children. Second, the precision for body composition analysis is twice as good by plethysmography as it is by hydrodensitometry (for example, for fat mass: $0.38 \mathrm{~kg} v 0.68 \mathrm{~kg}$, respectively). Third, the two methods can be used interchangeably to compare body composition results obtained in groups of healthy children because the two methods provided virtually identical results (mean (SD) fat mass by plethysmography and hydrodensitometry: 6.9 (4.0) and $6.7(4.2) \mathrm{kg}$, respectively). However, it is recommended that they should only be used interchangeably with caution because individual differences can be large in some subjects, as shown by the results of the four individuals that appear to be well outside the main body of results (fig 1). Although our study does not allow definitive determination of which of the two methods is more accurate, closer scrutiny of our results in conjunction with those obtained using deuterium dilution and dual energy $x$ ray absorptiometry $^{6}$ (results not shown here) tentatively suggests that the four large differences between plethysmography and hydrodensitometry might be the result of overestimation by one method combined with underestimation by the other, and not that one method is right and the other systematically wrong. Despite taking precautions to minimise the practical difficulties associated with each method, it is possible that certain of these sources of subject non-compliance went essentially unnoticed or that some operator error occurred. However, because each hydrodensitometric measurement was performed in duplicate with apparently good precision, it is also possible that these particular differences between methods might have been attributable to some biological variation not able to be taken into account. Fourth, the adult data support the conclusions obtained in children: that the precision of body volume by plethysmography is similar in adults and children, and better than that observed in hydrodensitometry.

The equations used for predicting body fat (\%) from density were applied appropriately to either adults or children, according to their respective derivation from mean densities for fat free mass. This distinction was made because of the apparent need for child specific constraints, mainly because of differences in composition of the fat free mass (such as greater hydration fraction in children), a contention originally expounded by Fomon et $a l,{ }^{14}$ and subsequently reinforced by the findings of-for example, Boileau and colleagues ${ }^{15}$ and Wells et al. ${ }^{6}$ In theory, a single child specific equation is not appropriate for the entire age range of 8 to 12 years because of subtle trends predicted in fat free mass for sex and age. ${ }^{14}$ However, these expected trends were 
too small to be observable in a recent study sample of 30 children in this age range, and so the equation used was the one that showed no evidence of bias against the four component model. ${ }^{6}$ More importantly, this equation was used to compare two methods of assessing body volume. Although \%fat values might be slightly inaccurate as a result of its application over the entire age range, the same equation was used for both the hydrodensitometric and plethysmographic methods, so that any differences in \%fat estimates were wholly attributable to differences between these methods, and not the equation, which is simply a way of expressing volume differences in terms of fatness.

The two component model of body composition used in our study assumes that tissues have a constant density. This assumption is not strictly true, because the fat free component composition changes with age, ${ }^{14}$ and is associated with substantial inter-individual variability. ${ }^{46}$ More complex models of body composition analysis, such as three and four component models, have been developed to overcome this variability. ${ }^{4}$ However, all these models require body density, and therefore body volume, to be measured. Use of plethysmography instead of hydrodensitometry should improve the precision of body composition analysis with any of the two, three, or four component models. For example, the variability of fat mass measurement using hydrodensitometry for the three component and the four component models $(0.45 \mathrm{~kg}$ and $0.54 \mathrm{~kg}$, respectively) ${ }^{6}$ would be improved using plethysmography $(0.27 \mathrm{~kg}$ and $0.31 \mathrm{~kg}$, respectively). In addition, the variability of estimates of protein mass would be similarly reduced from $0.54 \mathrm{~kg}$ to $0.28 \mathrm{~kg}$ (four component model only).

Methodological imprecision accounts for just under half of the observed variability between plethysmography and hydrodensitometry in children. Although hydrodensitometry was performed by the same experienced investigator for all subjects, it is important to minimise a number of other potential sources of error associated with this multi-technique method (for example, by ensuring that lung volume is measured at the exact moment of recording body weight at full submersion). Plethysmography was perceived as a simple technique with a minimal risk of technical errors, as long as the manufacturer's instructions were followed. Indeed, preliminary evidence obtained from 28 children in the age range 4 to 14 years indicates that, because there is no significant effect of age on method precision (JCK Wells and NJ Fuller, unpublished, 1999), biological variability is fairly consistent over the relatively wide ( 8 to 12 year) age range of children in our study.

The balance of the variability observed between methods can be explained by factors related to biological aspects of the measurements. For example, lung volume was measured in hydrodensitometry but predicted using adult specific equations for the correction factor applied in plethysmography. How- ever, although TGV was lower (mean, 0.28 litre) when predicted by the equations of Rosenthal et al, ${ }^{11}$ derived in 772 white schoolchildren of UK origin, than when predicted by the adult based software, use of these child specific equations did not alter the conclusions of our study. Furthermore, when alternative child specific predictions (for example, those of Cogswell and colleagues ${ }^{17}$ ) were used instead of those of Rosenthal et al, ${ }^{11}$ the results obtained were essentially the same.

TGV can either be predicted by the BODPOD software, or measured by a separate plethysmographic manoeuvre with the subject sitting inside the instrument. Although there is substantial inter-individual variation in lung volume, ${ }^{9}$ predicted or measured TGV gives similar estimation of body fat in healthy adults. ${ }^{7}$ However, the error introduced by using a predicted instead of a measured value for FRC is not yet known in children, and there remains a potential disadvantage in using measured lung volume, in that it is assessed separately from body volume, when the lungs might contain different volumes of air. In contrast, the hydrodensitometry method used here obtains a measurement of lung volume concurrently with body weight when submerged.

Another source of biological variability between methods might be in the assumption of gastrointestinal gas volume. Although $100 \mathrm{ml}$ is generally taken into account in hydrodensitometry, ${ }^{4}$ there is a large variation in reported values (for example, mean (SD) 115 (127) $\mathrm{ml}^{18} ; 90$ (54) $\mathrm{ml}^{19} ; 250$ (190) $\mathrm{ml}^{20}$ ). Traditionally, gastrointestinal gas volume is ignored when whole body air displacement plethysmography is used to determine lung volumes, ${ }^{21}$ because it is not in communication with ambient air and, therefore, should not influence pressure changes inside the chamber. However, the presence of gastrointestinal gas affects the volume of the abdomen and, therefore, body volume. An error of $100 \mathrm{ml}$ in either hydrodensitometry or plethysmography assessments of body volume would produce an error of approximately $0.04 \mathrm{~kg}$ fat in a 10 year old child with a weight of $39.5 \mathrm{~kg}$ and height of $1.43 \mathrm{~m}$.

Skin characteristics might also vary between individuals (for example, as a result of different temperature, blood flow, composition, and hairiness), which in turn might affect the value of the surface area artifact constant. ${ }^{7}$ For example, use of the $\mathrm{Du}$ Bois and $\mathrm{Du}$ Bois formula ${ }^{10}$ to calculate surface area in children $120-140 \mathrm{~cm}$ in height is likely to overestimate body surface area by a mean (SD) of 3\% $(7 \%),{ }^{22}$ translating into a $16(37) \mathrm{ml}$ overestimation of body volume, which is equivalent to 0.08 (0.18) fat. In relative terms, for a child comprising $6.9 \mathrm{~kg}$ fat, this is equivalent to a mean overestimation of $1.2 \%$, but with estimates likely to fall within the range $( \pm 2 \mathrm{SD}$ ) $-4.0 \%$ to $6.4 \%$, each side of the bias. Of course, body hair is likely to be more of a problem in adult men than in children. Body shape might also be responsible for some of the biological variability, by its influence on skin temperature and lung capacity. The effects of 
such factors, including that of raised body temperature if whole body plethysmography is to be used in patients, remain to be assessed.

In practice, body density measurements provided by air displacement plethysmography can be applied in the same way as those obtained using hydrodensitometry; for example, in the two component model, body composition estimates would still depend on the same assumptions regarding density and hydration fraction of the fat free mass. Furthermore, in a similar manner to hydrodensitometric measurements, body density can be combined with other measures to minimise use of uncertain assumptions-for example, with total body water in the more accurate three component model, or with total body water and total body bone mineral content in the four component model for even greater accuracy. ${ }^{6}$ Therefore, accurate measurements of body composition provided by four component modelling based on the easily performed, noninvasive air displacement plethysmography method would appear to be feasible in the clinical setting. However, it might still have limited use if clinical conditions adversely affect certain assumptions on which it is based (for example, those that might raise body temperature or alter lung function). Furthermore, although children as young as 4 years old have been easily measured using air displacement plethysmography, it has not yet been possible to validate it against an appropriate reference in such children because hydrodensitometry is not considered to be sufficiently practicable in all children of this young age.

Therefore, our findings suggest that whole body air displacement plethysmography is a promising technique, which makes body composition analysis in children more accessible to clinicians and other investigators, therefore making it a real possibility that body composition analysis can be part of clinical assessment. The ease of use of air displacement plethysmography, coupled with its reproducibility, subject compliance, and non-invasive nature, especially for diseased or traumatised children, would appear to outweigh the relatively low cost involved, particularly in comparison with certain other types of clinical instrumentation, such as magnetic resonance imaging.
1 Davies PSW, Evans S, Broomhead S, et al. Effect of growth hormone on height, weight, and body composition in Prader-Willi syndrome. Arch Dis Child 1998;78:474-6.

2 Jebb SA, Elia M. Techniques for the measurement of body composition: a practical guide. Int f Obes 1993;17:611-21. 3 Siri WE. Body composition from fluid spaces and density: analysis of methods. In: Brozek J, Henschel A, eds. Techniques for measuring body composition. Washington: National Acadamy of Science, 1961:223-43.

4 Fuller NJ, Jebb SA, Laskey MA, Coward WA, Elia M. Fourcomponent model for the assessment of body composition in humans: comparison with alternative methods, and evaluation of the density and hydration of fat-free mass. Clin Sci (Colch) 1992;82:687-93.

5 McCrory MA, Gomez TD, Bernauer EM, Molé PA. Evaluation of a new air displacement plethysmograph for meas27:1686-91.

6 Wells JCK, Fuller NJ, Dewit O, Fewtrell MS, Elia M, Cole TJ. Four-component model of body composition in children: density and hydration of fat-free mass and comparison with simpler models. Am $\mathcal{F}$ Clin Nutr 1999;69:904-12.

7 Dempster P, Aitkens S. A new air displacement method for he determination of human body composition. Med Sci Sports Exerc 1995;27:1692-7.

8 McCrory MA, Molé PA, Gomez TD, Dewey KG, Bernauer EM. Body composition by air-displacement plethysmography by using predicted and measured thoracic gas volumes. $\mathcal{F}$ Appl Physiol 1998;84:1475-9.

9 Crapo RO, Morris AH, Clayton PD, Nixon CR. Lung volumes in healthy nonsmoking adults. Bull Eur Physiopathol Respir 1982;18:419-25.

10 Du Bois D, Du Bois EF. A formula to estimate the approximate surface area if height and weight be known. Arch Intern Med 1916;17:863-71.

11 Rosenthal M, Cramer D, Bain SH, Denison D, Bush A, Warner JO. Lung function in white children aged 4 to 19 years: II- single breath analysis and plethysmography. Thorax 1993;48:803-8.

12 Zapletal A, Paul T, Samanek M. Normal values of static pulmonary volumes and ventilation in children and adolescents. Ceskoslovenská Pediatrie 1976;31:532-9.

13 Bland JM, Altman DG. Statistical methods for assessing agreement between two methods of clinical measurement. Lancet 1986; i:307-10

4 Fomon SJ, Haschke F, Ziegler EE, Nelson SE. Body composition of reference children from birth to age 10 years. Am f Clin Nutr 1982;35:1169-75.

15 Boileau RA, Lohman TG, Slaughter MH, Ball TE, Going SB, Hendrix MK. Hydration of the fat-free body in children during maturation. Hum Biol 1984;56:651-66.

16 Jebb SA, Elia M. Multi-compartment models for the assessment of body composition in health and disease. In: Davies PSW, Cole TJ, eds. Body composition techniques in health and disease. Cambridge: Cambridge University Press, 1995: 240-54.

17 Cogswell JJ, Hull D, Milner AD, Norman AP, Taylor B. Lung function in childhood: 2 . Thoracic gas volumes and helium functional residual capacity measurements in healthy children. Br F Dis Chest 1975;69:118-24

18 Bedell GN, Marshall R, DuBois AB, Harris JH. Measurement of the volume of gas in the gastro-intestinal tract. Values in normal subjects and ambulatory patients. F Clin Invest 1956;35:336-45.

19 Levitt MD. Volume and composition of human intestinal gas determined by means of an intestinal washout technic. N Engl F Med 1971;284:1394-8.

20 Chowdhury B, Sjöström L, Alpsten M, Kostanty J, Kvist H, Löfgren R. A multicompartment body composition technique based on computerized tomography. Int $\mathcal{f}$ Obes 1994;18:219-34.

21 Beardsmore CS. Lung function from infancy to school age in cystic fibrosis. Arch Dis Child 1995;73:519-23.

22 Elia M. Energy expenditure in the whole body. In: Kinney JM, Tucker HN, eds. Energy metabolism. Tissue determinants JM, Tucker HN, eds. Energy metabolism. Tissue determinants
and cellular corollaries. New York: Raven Press, 1992:19-59. 